\title{
DESENVOLVIMENTO E APLICAÇÃO DE SOFTWARE PEDAGÓGICO PARA A ALFABETIZAÇÃO DEALUNOS PÚBLICO-ALVO DA EDUCAÇÃO ESPECIAL ${ }^{1}$
}

\author{
Angelo Antonio Puzipe Papim \\ Universidade Estadual Paulista, Marília \\ angelopapim@gmail.com
}

\begin{abstract}
RESUMO
O processo de ensino e aprendizagem, realizado em salas de recursos multifuncionais, no cenário da educação especial, embora utilize as Tecnologias Digitais da Informação e Comunicação, não retira o papel de coadjuvante da interação e mediação sociocultural. O ser humano, indivíduo que ensina e que aprende, permanece no plano principal, administrando os instrumentos culturais adequados para promover o desenvolvimento sociocultural de alunos com deficiência intelectual, em processo de alfabetização. Em virtude disso, com o objetivo de compreender o processo de ensino e aprendizagem da linguagem escrita, empregando um software pedagógico na qualidade de mediador, realizou-se o estudo de caso de professores de educação especial, no ensino da linguagem escrita para alunos com deficiência intelectual. Trata-se de uma pesquisa qualitativa e descritiva, com base na análise causal da construção da linguagem escrita na ação e pensamento de alunos com deficiência intelectual. Conclui-se que o professor, através de indicativos de interação social, estabelece a qualidade do mediador e sua importância ao processo de ensino e aprendizagem.
\end{abstract}

Palavras-chave: Software pedagógico. Educação especial. Alfabetização.

\section{DEVELOPMENT AND APPLICATION OF EDUCATIONAL SOFTWARE FOR THE LITERACY OF SPECIAL EDUCATION TARGET AUDIENCE STUDENTS}

\begin{abstract}
The process of teaching and learning carried out in multifunctional resource rooms, in the special education setting, although using the Digital Information and Communication Technologies, does not remove the supporting role of socio-cultural interaction and mediation. The human being, an individual who teaches and learns, remains at the main level, managing the appropriate cultural instruments to promote the socio-cultural development of students with intellectual disabilities, in the process of literacy. As a result, in order to understand the teaching and learning process of

\footnotetext{
${ }^{1}$ Este artigo é a versão expandida de uma comunicação oral apresentada no VII Simpósio de Educação Inclusiva e Adaptações/ V Simpósio Internacional de Educação a Distância. São Paulo, UNESP, 2019.
} 
written language, using pedagogical software as mediator, a case study of special education teachers was carried out in the teaching of written language for students with intellectual disabilities. This is a qualitative and descriptive research, based on the causal analysis of the construction of written language in the action and thinking of students with intellectual disabilities. It is concluded that the teacher, through social interaction indicatives, establishes the mediator's quality and its importance to the teaching and learning process.

Keyword: Pedagogical Software. Special Education. Literacy.

\section{DESARROLLO Y APLICACIÓN DE SOFTWARE PEDAGÓGICO PARA LA ALFABETIZACIÓN DE ALUMNOS DE EDUCACIÓN ESPECIAL}

\section{RESUMEN}

El proceso de enseñanza y aprendizaje, llevado a cabo en salas de recursos multifuncionales, en el escenario de educación especial, aunque utiliza Tecnologías Digitales de Información y Comunicación, no elimina el papel de apoyo de la interacción y mediación sociocultural. El ser humano, uma persona que enseña y aprende, permanece en el plan principal, administrando los instrumentos culturales apropiados para promover el desarrollo sociocultural de los estudiantes con discapacidad intelectual, en el proceso de alfabetización. Como resultado, con el objetivo de comprender el proceso de enseñanza y aprendizaje del lenguaje escrito, utilizando un software pedagógico como mediador, se llevó a cabo un estudio de caso de maestros de educación especial en la enseñanza del lenguaje escrito para estudiantes con discapacidades intelectual. Es una investigación cualitativa y descriptiva, basada en el análisis causal de la construcción del lenguaje escrito en la acción y el pensamiento de los estudiantes con discapacidad intelectual. Se concluye que el maestro, a través de indicadores de interacción social, establece la calidad del mediador y su importancia para el proceso de enseñanza y aprendizaje.

Palabras clave: Software pedagógico. Educación especial. Literatura.

\section{INTRODUÇÃO}

De acordo com a perspectiva da Teoria Histórico-Cultural (THC), o desenvolvimento psicológico humano está vinculado às inter-relações sociais e ao uso intencional de instrumentos culturais, como a linguagem, em seus diferentes suportes. A construção das funções psicológicas superiores (FPS) acontece, quando as 
funções psicológicas naturais (FPN) adquirem, através de vivências intrapessoais, os contornos de ações especificamente internalizadas, mediante as operações concretas realizadas no contexto sociocultural. Essa relação dialética entre o potencial biológico e o sociocultural define as características do psiquismo. Assim, o processo de ensino e aprendizagem, enriquecido por instrumentos de mediação, oferece os meios para transformar aquilo que está em potência em ação e pensamento (VALSINER, 2006).

Segundo essa perspectiva, o mediador - as coisas da cultura ou o professor - desempenha centralidade no processo educacional, dado que carrega a intenção cultural para o ato do professor de ensinar ao aluno um conteúdo acadêmico. Direcionada pela interação com o professor, a ação do aluno deve apreender, na intenção, a motivação presente no mediador, a fim de operacionalizá-la na situação de aprendizagem, transformando o meio através do trabalho consciente. Essa relação de ensino e aprendizagem configura, no cenário educacional atual, um desafio para professor e aluno, principalmente quando essa dimensão é transposta para a educação especial (VYGOTSKY, 2010).

A aprendizagem do aluno com deficiência intelectual (DI) exige dos professores ações criativas para produzir mediadores capazes de motivar a ação intencional de seus alunos, em contexto educacional. Em virtude disso, as Tecnologias Digitais da Informação e Comunicação (TDIC) assumem um papel importante nas interações sociais de ensino e aprendizagem. As novas gerações de professores e alunos com DI estão desde cedo imersas na cultura digital, seja para estudo e comunicação, seja para entretenimento. Infelizmente, apesar de a educação especial dispor de sala de recursos multifuncionais (SRM), são poucas as instituições escolares que conseguiram incorporar a utilização de TDIC ao currículo e às práticas pedagógicas (TONUCCI, 2015).

Portanto, no cenário educacional atual, apesar de a tecnologia fazer parte da realidade sociocultural de professores, alunos, pais etc., ela não integra o movimento de ensino e aprendizagem, tornando-se um objeto estranho ao contexto educacional, ainda permeado por modelos pedagógicos analógicos - livros e apostilas - e centrados na figura do professor, ao qual cabe a condução da aprendizagem do aluno. Do ponto de vista pedagógico, comentam Silva e Camargo (2015), a adoção de TDIC na prática de ensino precisa acompanhar estratégias de aprendizagem que correspondam às condições contextuais de professores e alunos.

Para Vygotsky $(1995,2003)$, a aprendizagem envolve a atividade que conduz a função dos instrumentos culturais do plano social para o pessoal, com o objetivo de viabilizar o comportamento cultural e a autorregulação. Na visão de Vygotsky (2017) e Daniels (2016a, 2016b), os alunos com DI, ao longo do seu desenvolvimento sociocultural vivenciado na escola, precisam construir, no curso da inter-relação social, as funções psicológicas relacionadas ao uso público e interno da linguagem, 
as quais estão presentes na ação do professor e em circulação na cultura escolar, de forma geral. Nesse caso, a inter-relação social possibilita ao professor ensinar, com a criança com deficiência intelectual, o caminho mais adequado para promover a sua aprendizagem e o desenvolvimento sociocultural do uso dos instrumentos da cultura.

Nessa perspectiva, o professor pode estabelecer uma relação de ensino da linguagem escrita, por meio de scaffolding (andaime), processo de interação no qual o docente ou um par, ambos mais experientes, ajudam o aprendiz em sua Zona de Desenvolvimento Imanente (ZDI), conforme sua necessidade, retirando a ajuda à medida que ela se torna desnecessária. É algo similar à função de um andaime, o qual pode ser retirado de uma construção, quando sua função não é mais necessária à obra (BALADAN, 1995; WERTSCH, 1994; SMITH, 1979).

Por conseguinte, esta pesquisa, com o objetivo de compreender o processo de ensino e aprendizagem da linguagem escrita em alunos com DI, visou a implementar procedimentos pedagógicos, em SRM, capazes de viabilizar o emprego de recursos de TDIC, na qualidade de mediadores, a fim de facilitar o processo de construção de funções psicológicas relacionadas ao uso da linguagem escrita, em contexto cooperativo de ensino eaprendizagem.

\section{METODOLOGIA}

A presente pesquisa consistiu de um estudo de caso de professores de educação especial, atuantes em SRM, no ensino da linguagem escrita para alunos com DI, utilizando recursos de TDIC como mediadores, para a construção das FPS. Foram sujeitos da pesquisa um professor de educação especial e duas alunas com DI, na faixa etária de oito e nove anos.

A pesquisa ocorreu na SRM de uma escola municipal do interior do estado de São Paulo. Os instrumentos de coletas de dados foram constituídos pela análise da elaboração coletiva da ação pedagógica, realizada entre pesquisador e professor, observação da ação pedagógica e análise da aprendizagem da criança com DI, por intermédio de avaliação inicial e final, realizada pelo professor, ao início e final da ação pedagógica.

Os dados obtidos, na sessão de intervenção apresentada, foram qualitativamente analisados, através do protocolo Índice de Apropriação da Aprendizagem (IAA) (Quadro 1), divididos em três categorias: receptivo, acumulativo ou explorador, pontuadas de 0 a 10, sendo: 0 - ausência de conduta: receptivo, 5 conduta interpessoal: acumulativo e 10 - conduta intrapessoal: explorador. E, também, descritivo, com base na gênese causal, processo responsável pela construção da FPS, enquanto meio para construção da ação e pensamento da linguagem escrita na criança com DI. 
Quadro 1 - Protocolo Índice de Apropriação da Aprendizagem.

\begin{tabular}{|l|c|l|}
\hline \multicolumn{3}{|c|}{ Índice de Apropriação da Aprendizagem (IAA) } \\
\hline \multicolumn{1}{|c|}{ Receptivo: } & Acumulativo: & \multicolumn{1}{c|}{ Explorador: } \\
\hline $1-\square$ & $1-\square$ & Ações de autorregulação com o recurso pedagógico: \\
$2-\square$ & $2-\square$ & \\
$3-\square$ & $3-\square$ \\
$4-\square$ & $4-\square$ \\
$5-\square$ & $5-\square$ & \\
\hline & \\
\hline Anotações: & \\
\hline
\end{tabular}

Fonte: Organizado pelo autor.

\section{RESULTADOS E DISCUSSÃO}

A elaboração da ação pedagógica, seguindo a estrutura de três dimensões (conteúdo, objetivo e procedimentos), proporcionou ao professor compreender como utilizar os recursos de TDIC com intenção pedagógica, estabelecendo estratégias de ensino nas quais o material escolhido para trabalhar com a criança com DI compusesse um contínuo de ações e interações cooperativas direcionadas para um objetivo, o qual precisava ser partilhado com o aprendiz, ao longo da execução da atividade, e, por intermédio da interação cooperativa, restabelecer a conexão da ação realizada, enquanto parte dos procedimentos pedagógicos, com o objetivo e o conteúdo.

O Plano de Ação Pedagógica (PAP) (Quadro 2) foi organizado do seguinte modo: conteúdo: Leitura de palavras, sílabas, coordenação motora fina - ligar figura à palavra; Objetivo: 1 - Ler, junto ao professor, trechos da história; 2 - Ser capaz de ligar as imagens às palavras; 3 - Reconhecer a formação das sílabas e preencher corretamente o traçado das letras com a cor indicada; Procedimentos: Atividade escrita: Ligar o desenho com a palavra correta e preencher as letras vazadas com a cor indicada.

Quadro 2 - Plano de Ação Pedagógica.

\begin{tabular}{|l|l|l|}
\hline \multicolumn{3}{|c|}{ Plano de Ação Pedagógica } \\
\hline Conteúdo & \multicolumn{1}{|c|}{ Objetivo } & \multicolumn{1}{c|}{ Procedimentos } \\
\hline Leitura de palavras, & 1 - Ler, junto ao professor, & Atividade escrita: Ligar o \\
sílabas, coordenação & trechos da história; & desenho com a palavra \\
motora fina - ligar figura & 2 - Ser capaz de ligar as & correta e preencher as letras \\
à palavra. & imagens às palavras; & vazas com a cor indicada. \\
& 3 - Reconhecer a formação & \\
& das sílabas e preencher & \\
& corretamente o traçado das & \\
& letras com a cor indicada. & \\
\hline
\end{tabular}

Fonte: Organizado pelo autor. 
O professor, mediante o planejamento da ação, pode ativamente incentivar, nos alunos com DI, com o objetivo de desenvolver as suas funções psicológicas, a ação com a linguagem escrita. A fim de potencializar as habilidades de autorregulação, o processo de ensino cultural precisa ser planejado com antecedência, e a sua prática deve se dar em conformidade com os objetivos inicialmente traçados, o que faculta fazer a regulação externa da conduta, através da mediação pedagógica (PAPIM, 2019).

Dessa forma, o professor, ao formular as atividades educacionais com uma determinada intenção, tem que encontrar meios adequados para partilhá-las com os alunos, pois a mediação pedagógica é um processo ativo e dinâmico, no qual os mediadores desempenham uma função importante na conduta coletiva. Por isso, o recurso de TDIC escolhido para essa atividade foi o software pedagógico de alfabetização, denominado A Tata Tatu (Figura 1), desenvolvido pelo autor da pesquisa.

Figura 1 - Abertura do software pedagógico de alfabetização.

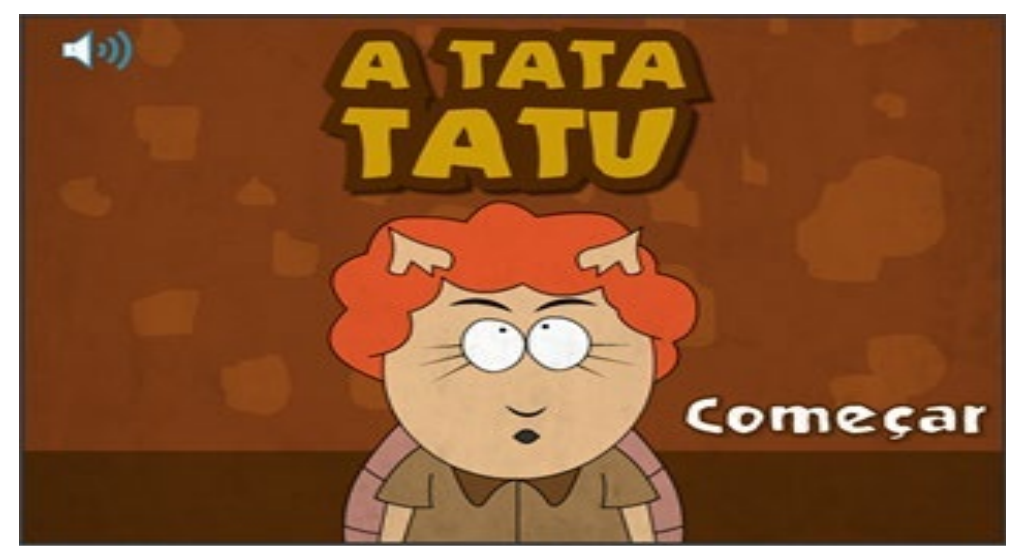

Fonte: Elaborada pelo autor.

Aelaboração da atividade pedagógica pelo professor não serve apenas para orientar a conduta do aluno, mas também para orientar a sua própria conduta, ao longo do processo de ensino e aprendizagem. A inter-relação na atividade compartilhada é sempre orientada por uma linha-guia, que direciona a conduta tanto do professor quanto do aluno para um mesmo fim, isto é, compartilhar significados entre si.

Nesses termos, a conduta do professor é guiada por um instrumento externo - o PAP, planejado por ele com antecedência -. O planejamento do processo de ensino possibilita ao professor antever sua conduta e o ajuda a planificar formas diferentes para compartilhar um significado, enriquecendo a vivência do aluno. Em virtude disso, ao planejar uma interação social mediada, cria-se possibilidades de expor o objetivo da atividade e conduzir o aluno a fazer escolhas, empregando os instrumentos ofertados.

A atividade pedagógica foi constituída das seguintes ações: apresentar aos alunos formas de usar as palavras como instrumento para resolver situações- 
problema. Durante a realização da atividade o professor encorajou as crianças a verbalizarem enquanto pensavam nas alternativas e se valerem de apoios visuais, para facilitar o uso da linguagem como instrumento. Com o intuito de se tornar um instrumento social e psíquico, o diálogo será dominante, ao longo de todo o processo, nas ações do professor.

Com a intenção de iniciar a atividade, o professor se senta no chão, com o material de apoio disposto à sua frente, e solicita aos demais alunos formarem um círculo, começando da direita para a esquerda. O professor indica aos alunos em qual posição eles devem se sentar. Os alunos próximos ao professor, sentados ao seu lado esquerdo e direito, são os que precisam de maior apoio, e os mais distantes são os alunos que têm maior habilidade e são capazes de ajudar os demais. A organização dos alunos no círculo integrou a etapa de elaboração da atividade, e nenhuma ação tomada pelo professor foi aleatória ou improvisada, mas sistematizada com previsibilidade.

É essencial, na mediação, o material pedagógico estar acessível a todos, uma vez que faz parte do ensino e da aprendizagem o manuseio dos instrumentos, inclusive da linguagem, como condição imperativa do processo de vivência com o instrumento, que, no ensino cultural, é o meio pelo qual ocorre a internalização na psique pessoal. A organização tanto dos alunos quanto do material é um elemento importante para compartilhar o significado entre o professor e os alunos, porque permite ao professor ensinar condutas às crianças, ao incentivá-las a escolher, dentre os materiais oferecidos, o mais adequado para o cumprimento da atividade.

Ao demonstrar aos alunos a função de cada instrumento disponível para eles, o professor controla e direciona a conduta dos alunos, mantendo-a dentro dos objetivos da atividade. Ao organizar em círculo os alunos e o material, o professor conversa consigo, diante dos alunos, e lhes explica o motivo dessa conduta." À medida que discute as escolhas, o professor orienta a conduta do aluno, através de conversas úteis para compartilhar o significado das palavras.

Quando todos estão aclimatados à organização, o professor dá início a outra etapa da atividade. Ele retira do material disposto no centro do círculo um tablete com a história interativa já iniciada na tela. Ele demonstra a cena de abertura para todos e encoraja os alunos a falarem o que estão pensando. Depois de uma conversa sobre a abertura, o professor clica em começar, a fim de dar início à história (Figura 2). 
Figura 2 - Sequência de imagens da história.

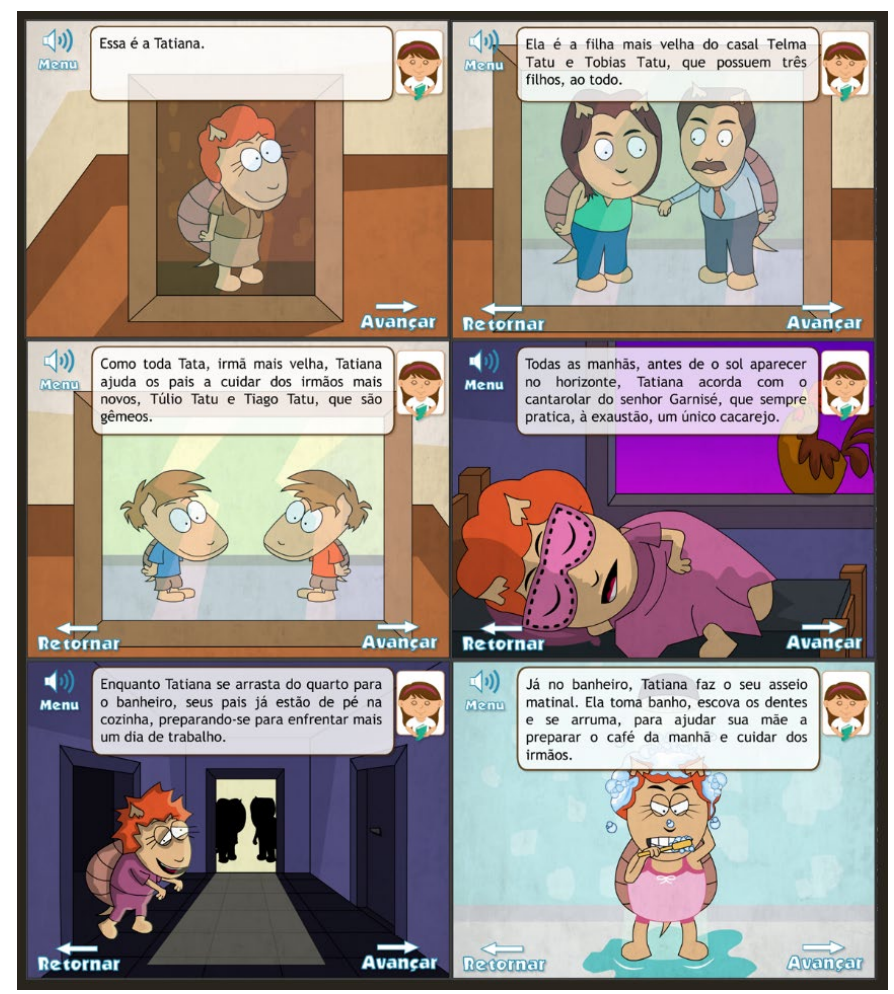

Fonte: Elaborada pelo autor.

A atividade com a história possui a finalidade de encorajar os alunos a falarem e escrever enquanto pensam. Para isso, o professor mantém a estratégia inicial de usar os componentes da história, com a intenção de oferecer aos alunos escolhas que deverão ser realizadas, apoiadas no emprego de palavras como instrumento. Imagens e palavras compõem, a cada cena da história, um conjunto de elementos que precisam a intervenção do professor, no sentido de compartilhar o significado com o aluno. $O$ professor pode solicitar aos alunos imaginar qual a finalidade de cada componente, antes de demonstrar sua função: é interessante incentivar que eles conversem entre si, para se beneficiarem da intenção uns dos outros.

Figura 3 - Áudio e legenda.

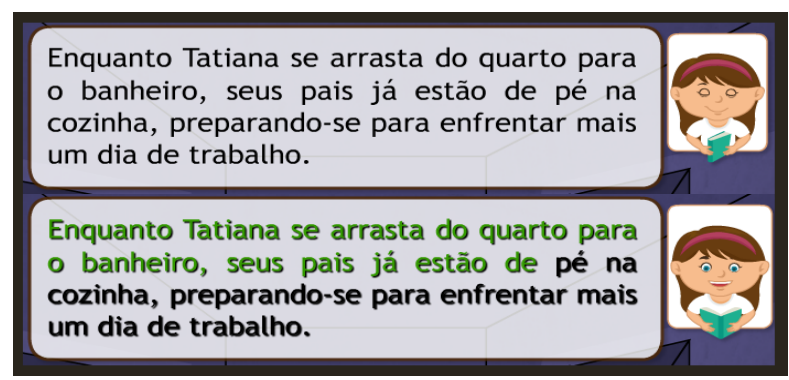

Fonte: Elaborada pelo autor.

Com a intenção de fazer os alunos olharem para a sua própria forma de pensar, orienta a criança a ouvir a narradora da história e acompanhar a legenda 
(Figura 3), e, depois, também, a falarem baixinho o que entenderam, sem atrapalhar os demais, todavia, ouvindo as suas próprias falas, no sentido de torná-las aptas a denominarem a sua própria conduta.

A história narra o dia a dia da Tatiana. No início da história, são apresentadas as atividades que ela desempenha sozinha; na sequência, as que ela precisa realizar, a fim de ajudar sua mãe com os afazeres e o cuidado com os irmãos. Há quatro situações-problema na história (Figura 4), cujo processo de resolução contribui com o objetivo de compartilhar o significado de quatro palavras: amassar, procurar, assear e alimentar. A ação do professor, nessas quatro situações-problema, foi intensificada, com a finalidade de descrever a conduta dos alunos no manejo dos materiais, com o maior detalhamento possível, quando a criança não entendia o que estava acontecendo.

Figura 4 - Situações-problema.

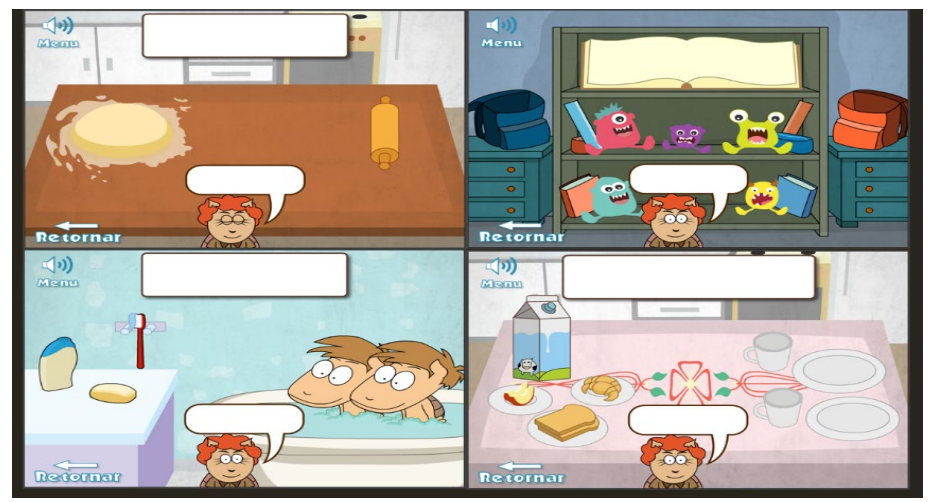

Fonte: Elaborada pelo autor.

O professor não deve ter receio de descrever o comportamento do aluno, a fim de que ele compreenda sua ação, através de sua descrição verbal. Caso uma criança se disperse, descreve a sua conduta em detalhes e indica a ela a conduta que deve apresentar. Conceitos novos precisam ser relacionados a uma ação e a um conceito já conhecidos. Isso deve ser uma preocupação do professor, ao realizar a atividade, já que, ao estabelecer essa relação, ele contextualiza o significado presente no conceito, demonstrando sua função. Com a intenção de tornar o significado claro, inserem-se quantos apoios forem necessários para cumprir os objetivos (Ler, junto ao professor, trechos da história; Ser capaz de ligar as imagens às palavras; Reconhecer a formação das sílabas e preencher corretamente o traçado das letras com a cor indicada.).

No sentido de facilitar a internalização do significado pelos alunos, o professor inseriu o alfabeto silábico, organizando as palavras uma a uma, acompanhando a sequência na qual cada uma aparece na história e explicando com outros exemplos o que significava cada palavra. Enquanto falava o significado da palavra, demonstrava esse valor com o material escrito ou com o próprio corpo, em uma ação equivalente, 
relacionado a um determinado contexto sociocultural, como aparece na história, escrevendo as palavras.

Na opinião do professor, a parte mais difícil da realização da atividade foi avaliar a internalização do conceito compartilhado na atividade, e se a linguagem como ferramenta de autorregulação fez parte da elaboração de entendimento do aluno, ao manusear a palavra, seja falando seja escrevendo.

Ciente do papel imprescindível da linguagem como instrumento para o desenvolvimento do aluno, o professor, na ação pedagógica, compreende que deve oferecer vivências com muitas oportunidades para o aluno praticar as formas da linguagem enquanto componentes indispensáveis das interações de ensino, aprendizagem e desenvolvimento das FPS, relacionadas à linguagem escrita. $O$ índice de apropriação de aprendizagem (Tabela 1) dos alunos aponta para um avanço no desenvolvimento, quando são comparadas as avaliações iniciais (Al) e finais (AF).

\section{Gráfico 1 - Comparação da Avaliação inicial e final.}

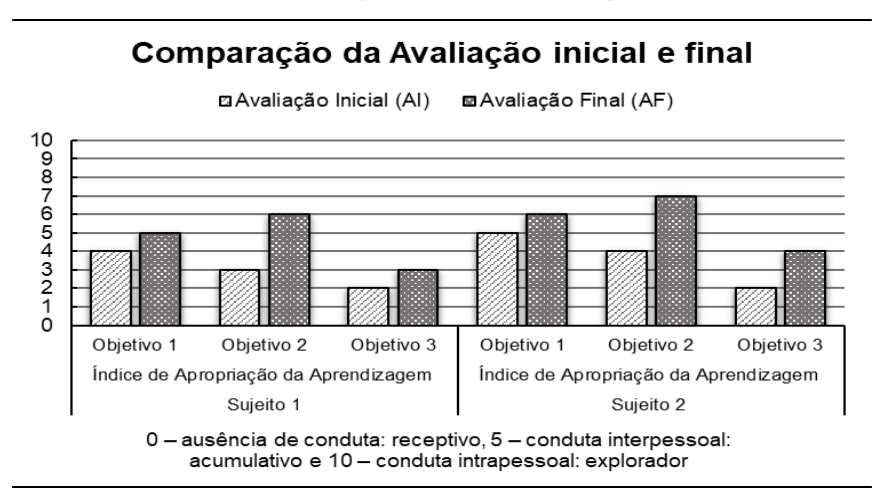

Fonte: Organizado pelo autor.

Ao se analisar o gráfico, a partir dos objetivos estabelecidos pelo professor no PAP, percebe-se que há, entre os alunos com DI, uma diferença na ZDI. O sujeito 1 apresenta, no IAA, um processo inicial da construção das condutas estipuladas pelo professor nos objetivos, circunstância na qual o aluno com DI indica a necessidade da cooperação do parceiro mais experiente, durante execução da atividade pedagógica, sendo um ator mais receptivo na interação com o professor, de sorte a acumular vivências significativas para a execução da atividade.

O sujeito 2, nos primeiros dois objetivos, demonstra ao professor a construção da conduta interpessoal para a interpessoal, condição que propicia uma gradual diminuição da colaboração do professor, frente às ações do aprendiz, na execução das atividades pedagógicas, já que ele apresenta um acúmulo de vivências que permite uma maior exploração da atividade. Porém no objetivo três, no qual o aprendiz está mais próximo da ausência de conduta, a cooperação do professor aumenta, auxiliando as ações do aluno com DI, ao receber e acumular interações 
que possibilitam sustentar, futuramente, ações de exploração. Consequentemente, o professor, ciente do papel imprescindível da interação como instrumento regulador da aprendizagem do aluno, compreende que deve oferecer ao aprendiz atividades pedagógicas repletas de oportunidades, para vivenciar diferentes formas de internalizar a função ensinada, enquanto componentes indispensáveis à aprendizagem.

\section{CONSIDERAÇÕES FINAIS}

Na escola, a conduta do aluno é regulada pela conduta do professor, em cooperação, movimento precursor da capacidade de o aprendiz internalizar as funções sociais e, assim, ser capaz de autorregular a conduta, por meio de funções psíquicas. Em vista disso, o papel do professor, no ensino e aprendizagem cultural, consiste em elaborar processos pedagógicos com instrumentos de mediação os quais precisam ser passados aos alunos, por meio de vivências, com o objetivo de refletir em suas consciências os significantes culturais compartilhados ao longo da ação pedagógica.

A autorregulação da conduta é consequência direta dos processos de mediação internalizados pelas pessoas. O modelo de conduta social presente na consciência do adulto mantém os mesmos princípios originados na interação do aluno com DI com o outro, o professor.

Por esse motivo, os recursos de TDIC, enquanto elementos de mediação, precisam pertencer a ações pedagógicas intencionais, organizadas em conteúdo, objetivos e procedimentos, com a finalidade de motivar as ações cooperativas de ensino e aprendizagem, através de indicativos que demonstrem ao professor a qualidade da interação social, prática de scaffolding, durante a atividade pedagógica.

\section{REFERÊNCIAS}

BALABAN, N. Seeing the child, knowing the person. In: AYERS, W. To become a teacher. New York: Teachers College Press, 1995.

DANIELS, H. Vygotsky and Dialogic Pedagogy. In: SKIDMORE, D.; MURAKAMI, K. Dialogic Pedagogy: the Importance of Dialogue in Teaching and Learning. Buffalo: Multilingual Matters, 2016a.

DANIELS, H. Vygotsky and Pedagogy. New York: Routledge, 2016b. PAPIM, A. A. P. A ação pedagógica na perspectiva vygotskyana:compreensão da linguagem no ato de ensinar e aprender. 2019. Dissertação (Mestrado em Educação) - Faculdade de Filosofia e Ciências, Universidade Estadual Paulista, Marília, 2019.

SILVA, R. A.; CAMARGO, A. L. A cultura escolar na era digital: o impacto da aceleração tecnológica na relação professor-aluno, no currículo e na organização escolar. In: 
BACICH, L.; TANZI NETO, A.; TREVISANI, F. M. Ensino Híbrido: personalização e tecnologia na educação. Porto Alegre: Penso, 2015.

SMITH, D. D. The improvement of children's oral reading through the use of teacher modeling. Journal of Learning Disabilities, v. 12, n. 3, p. 39-52, 1979.

TONUCCI, F. Os alunos na escola do amanhã. In: JARAUTA, B.; IMBERNÓN, F. Pensando o futuro da educação: uma nova escola para o século XXI. Porto Alegre: Penso, 2015.

VALSINER, J. Modelos psicológicos, modelos educativos. Una perspectiva históricocultural. In: ÁLVAREZ, A. Hacia un currículo cultural: la vigencia de Vygotsky en educación. Madrid: Fundación Infancia y Aprendizaje, 2006.

VYGOTSKY, L. S. Obras Escogidas III. Madrid: Visor, 1995.

VYGOTSKY, L. S. Pensamento e linguagem. São Paulo: Martins Fontes, 2003.

VYGOTSKY, L. S. Aprendizagem e desenvolvimento intelectual na idade escolar. In: VYGOTSKY, L. S.; LURIA, A. R.; LEONTIEV, A. N.Linguagem, desenvolvimento e aprendizagem. São Paulo: Ícone, 2010.

VYGOTSKY, L. S. El Desarrollo de los Procesos Psicológicos Superiores.3. ed. Barcelona: Crítica, 2017.

WERTSCH, J. V. Explorations in socio-cultural studies. Madrid: Fundación Infancia y Aprendizaje, 1994.

\section{BIOGRAFIA DO AUTOR}

ANGELO ANTONIO PUZIPE PAPIM - Graduado em Psicologia, com especialização em Terapia Cognitivo-Comportamental; graduado em licenciatura plena em Pedagogia pela Faculdade de Filosofia e Ciências (UNESP) Marília; graduado em Ciências Sociais pela Faculdade de Filosofia e Ciências (UNESP) Marília; Mestrando em Ciências Sociais, na linha de Pensamento Social, Educação e Políticas Públicas, pela Faculdade de Filosofia e Ciências (UNESP) Marília; Mestrado em Educação, na linha de Educação Especial, pela Faculdade de Filosofia e Ciências (UNESP) Marília. Doutorando em Educação, na linha de Educação Especial, pela Faculdade de Filosofia e Ciências (UNESP) Marília. Tem experiência na área de Psicologia Clínica. Possui experiência em Psicologia Social e Educacional, atuando principalmente na área de Educação Especial e Desenvolvimento Humano.

Data de recebimento: 01/09/2020

Data de aprovação: 23/10/2020 